\title{
Vaccine Therapy in Advanced Melanoma - State of the Art
}

\author{
R. Dummer \\ Dermatologische Klinik, Universitätsspital Zürich
}

\section{Introduction}

Melanoma is an antigenic tumor derived from melanocytes. Early-stage melanomas are effectively removed by surgery. Melanoma metastases, however, are extremely difficult to treat. Only a minority of patients will respond to standard treatment options such as radiotherapy, chemotherapy, and the use of biological response modifiers [1].

\section{Melanoma is an Antigenic Tumor}

In the last decades a variety of melanoma antigens [2] have been characterized. Most of them are recognized by the immune system in form of peptides presented in the groove of the HLA class I molecule. The clinical application of tumor-infiltrating lymphocytes expanded in vitro in the presence of interleukin (IL)-2 has resulted in an elimination of even large tumor volumes [3]. Although the exact effector mechanism of tumor rejections is unclear, cytotoxic CD8-positive $\mathrm{T}$ lymphocytes are considered to be the major effector mechanism against this tumor [4]. Therefore, modern immunotherapy aims to activate these cell populations by vaccination approaches [5].

\section{Principles of Vaccination Against Cancer}

Unlike most vaccines for infectious diseases, cancer vaccination is a therapeutic strategy that activates immune responses against tumor antigens. These antigens are present in the organism for years and still remain ignored by the immune system. This ignorance is not completely understood. Tumor antigen loss variants, defects in HLA expression or secretion of local inhibitory molecules such as IL-10 [6] and peripheral localization of tumor cells [7] that does not allow significant amount of tumor antigens in lymphatic organs seem to be possible explanations. This peripheral location of tumor antigens results in the presentation of these antigens without costimulatory signals, leading to tolerance instead of activation [8]. The primary goal of all cancer vaccines is to present tumor antigens to $\mathrm{T}$ cells in a microenvironment that provides sufficient costimulation.

\section{Designs for Melanoma Vaccines}

There are in principle two major approaches to induce an effective immune response. One possibility is to introduce sufficient costimulation into tumor cells, for example by the transduction of cytokine genes and/or costimulatory cDNA molecules. The other possibility is to target the tumor antigens to appropriate bone marrow derived antigen-presenting cells (APCs). For melanoma from which large number of tumor cells can be obtained by surgery, vaccines can be produced by the admixture of patient cells with bystander cells such as fibroblasts transduced with cytokines or with cytokine proteins. Another possibility is to generate autologous tumor cells that are modified using cytokine genes or other immune stimulatory molecules [9]. The generation of autologous tumor cells is expensive, labor-intensive and time-consuming. Therefore, these cell-based cancer vaccines will find only a very limited acceptance in the clinical practice.

Many individual melanomas share tumor antigens [2] such as MAGE [10], gp100, tyrosinase [11], and others. Therefore, these antigens can be applied for vaccination. The first antigenspecific cancer vaccines tested clinically have been specific peptides presented by common HLA subtypes. This approach is hampered by the short half-life of the peptides and their binding abilities to HLA molecules in vivo. Only few studies report the induction of increased frequencies of cytotoxic $\mathrm{T}$ lymphocytes in the blood or clinical responses [4]. There is convincing evidence from animal models, that after the disappointing clinical trials of subcutaneously applied peptides this approach might be significantly improved, if the peptides are presented to the immune system for several days in an lymphatic organ [7]. Therefore, a pilot study analyzing intranodal continuous release of peptides has been initiated by Thomas Künding in our department.

Melanoma antigens may also be delivered by recombinant viral vectors using vaccinia virus and/or adenovirus. One major problem with this approach is the presence of neutralizing antibodies that are able to block the viral vaccines [4].

A number of bacterial strains such as Salmonella or Listeria have been tested in animal models to deliver vaccines. This promising approach has to be applied in phase I and II clinical trials.

\begin{tabular}{ll}
\hline KARGER & ( ) 1999 S. Karger GmbH, Freiburg \\
Fax +49761 4520714 & Accessible online at: \\
$\begin{array}{l}\text { E-mail kargergmbh@aol.com } \\
\text { www.karger.com }\end{array}$ & http://BioMedNet.com/karger \\
\end{tabular}

PD Dr. med. Reinhard Dumme

Dermatologische Klinik, Universitätsspital

Gloriastrasse 31

CH-8091 Zürich (Switzerland)

Tel. +41 1 255-2507, Fax -4403

E-mail dummer@derm.unizh.ch 
An elegant alternative might be so-called naked DNA since it is very resistant and easy to produce. The injection of naked DNA in skin or muscle encoding melanoma antigens eventually combined with cytokine cDNA induces local inflammation and activation of bone marrow derived APCs. Early clinical trials are under way.

Bone marrow derived APCs play a central role in the introduction of immune responses [12]. Therefore, dendritic cell based vaccines are now widely used in early clinical trials. These cells express high levels of HLA molecules and costimulatory molecules combined with optimal cytokine secretion for T cell activation [4]. The APC vaccines have been successfully used in B cell lymphoma patients and melanoma patients [13]. Additional trials will define the optimal activation status and the best antigen-loading procedures. An interim analysis of melanoma patients treated in Mannheim and Zurich convincingly demonstrates that the APCs are effective in the induction of an immune response against tumor antigens in more than $50 \%$ of the patients treated. A clinical response rate of 25-30\% was observed. Responses have been observed in patients treated with the APCs loaded with peptides or with tumor lysates, grown in medium containing fetal calf serum or autologous serum supplemented with various cytokines. Skin and blood tests revealed T-cell responses against HLA-I pre- sented peptides [13]. This treatment approach is extremely well tolerated and is performed in an out-patient setting. The intranodal injection of the APC vaccine under ultrasound control necessitates only weekly appointments. Comparative clinical trials will determine the sequence and the necessary frequencies of injections of APCs.

\section{Conclusion}

Based on this knowledge it is necessary to initiate working groups on APCs to define standards for their generation, application and loading conditions and initiate coordinate clinical trials to develop this promising approach. Due to the various immune escape mechanisms, these trials shall be accompanied by careful investigation of the immune response induced and the antigen profile of the individual tumors. In my personal opinion, vaccination approaches will only have a future if we succeed in a precise immunoprofiling of the individual tumors to identify suitable patients for this highly specific treatment. Vaccination therapy today still remains an experimental procedure that should be applied only in a limited number of hospitals that provide all facilities for a sophisticated evaluation of the immune response and the escape mechanisms of the tumor cells.

\section{References}

1 Dummer R, Nestle FO, Burg G: Therapie des kutanen Melanoms. Ther Umsch 1998;55:509-514.

2 Boon T, Coulie PG, Van den Eynde B:Tumor antigens recognized by $\mathrm{T}$ cells. Immunol Today 1997;18: 267-268.

3 Rosenberg SA, Packard BS, Aebersold PM, Solomon D, Packard BS, Topalian SL, Toy ST, Simon P, Lotze MT, Yang JC: Use of tumor-infiltrating lymphocytes and interleukin-2 in the immunotherapy of patients with metastatic melanoma. A preliminary report [see comments]. N Engl J Med 1988;319:1676-1680.

4 Pardoll DM: Cancer vaccines. Nat Med 1998;4: 525-531.

5 Nestle FO, Burg G, Dummer R: New perspectives on immunobiology and immunotherapy of melanoma Immunol Today 1999;20:5-7.
6 Geertsen R, Hofbauer G, Kamarashev J, Yue FY, Dummer R: Immune escape mechanisms in malignant melanoma. Int J Mol Med 1999;3:49-57.

7 Zinkernagel RM, Ehl S, Aichele P, Oehen S, Kundig T, Hengartner $\mathrm{H}$ : Antigen localisation regulates immune responses in a dose- and time-dependent fashion: A geographical view of immune reactivity. Immunol Rev 1997;156:199-209.

8 Speiser DE, Miranda R, Zakarian A, Bachmann MF, Odermatt B, Hanahan D, Zinkernagel RM, Ohashi PS: Self antigens expressed by solid tumors do not efficiently stimulate naive or activated T cells: Implications for immunotherapy. J Exp Med 1997;186 645-653.

9 Dummer R, Davis-Daneshfar A, Döhring C, Döbbeling U, Burg G. Strategien zur Gentherapie des Melanoms. Hautarzt 1995;46:305-308.
10 Hofbauer GF, Schaefer C, Noppen C, Böni R, Kamarasher J, Nestle FO, Spagnoli GC, Dummer R MAGE-3 immunoreactivity in formalin-fixed, paraffin-embedded primary and metastatic melanoma: Frequency and distribution. Am J Pathol 1997;151: 1549-1553.

11 Hofbauer GF, Kamarashev J, Geertsen R, Boni R, Dummer R: Tyrosinase immunoreactivity in formalin-fixed, paraffin-embedded primary and metastatic melanoma: Frequency and distribution. J Cutan Pathol 1998;25:204-209.

12 Schuler G, Steinman RM: Dendritic cells as adjuvants for immune-mediated resistance to tumors. J Exp Med 1997;186:1183-1187.

13 Nestle FO, Alijagic S, Gilliet M, Sun Y, Grabbe S, Dummer R, Burg G, Schadendorf D: Vaccination of melanoma patients with peptide- or tumor lysatepulsed dendritic cells. Nat Med 1998;4:328-332. 